\title{
Long-Term Performance and Deicing Effect of Sustained-Release Snow Melting Asphalt Mixture
}

\author{
Jian Zhou, Jing Li, Guoqiang Liu, Tao Yang, and Yongli Zhao \\ School of Transportation, Southeast University, Nanjing, Jiangsu 210096, China \\ Correspondence should be addressed to Yongli Zhao; yonglizhao2016@126.com
}

Received 20 February 2019; Revised 3 May 2019; Accepted 20 May 2019; Published 11 June 2019

Academic Editor: Ghassan Chehab

Copyright (C) 2019 Jian Zhou et al. This is an open access article distributed under the Creative Commons Attribution License, which permits unrestricted use, distribution, and reproduction in any medium, provided the original work is properly cited.

\begin{abstract}
To accelerate snow and ice melting, traditional chloride-based salts are spreaded on asphalt pavement surface, causing serious environmental pollution and infrastructure corrosion. For sustained-release snow melting asphalt mixture, the snow melting agent of Mafilon is directly added to asphalt mixture by replacing partial mineral powder to develop a new type of functional asphalt mixture. In this paper, through the Marshall test, immersion Marshall test, rutting test, trabecular bending test, and Cantabro test, the effects of Mafilon addition on asphalt pavement performance is systematically analysed. Meanwhile, salt precipitation rate is measured by conductimetry to estimate effective deicing period of the pavement. Finally, a new experimental device is designed to quantitatively evaluate snow melting effect of sustained-release snow melting asphalt pavement. The experimental results show that replacing $70 \%$ of the mineral powder with Mafilon by volume can achieve satisfactory snow melting effect without affecting usability of asphalt pavement.
\end{abstract}

\section{Introduction}

In winter, driving safety of pavements is a major concern for road agencies in many countries. Snow and ice on pavement in winter will lead to a significant decline in its skid resistance, which seriously jeopardizes driving safety and makes serious traffic accidents easy [1-4].

Nowadays, chloride snow melting agents are widely used all over the world due to the low price, convenience in using, and quick effect of it [5]. However, chloride snow melting agents can cause environmental pollution and infrastructure corrosion $[6,7]$. In addition, since the melted ice and snow are easy to freeze again as the temperature drops, the effect of melting snow and ice is affected by the ambient temperature. Therefore, to ensure traffic safety and reduce environmental pollution, it is imperative to study environmental-friendly deicing methods of road.

The sustained-release snow melting asphalt pavement refers to a new type of asphalt pavement capable of deicing. It is formed by adding salinized material to asphalt mixture in replacement of partial mineral material. The work principle of the pavement is show in Figure 1. During snowfall, the internal salt of the asphalt mixture gradually precipitates under the action of vehicle rolling and capillary pressure. When the salt diffuses to the road surface, it will lower the freezing point of water and melt snow/ice on pavement surface. Thereby, the bond between ice and road surface is destroyed, and the antislip function of the road surface is restored.

The research of snow melting pavement originated in Europe in 1960s [8]. Verglimit, developed by Swiss research institutes, can be added to asphalt pavement to reduce the freezing temperature of the pavement to $-20^{\circ} \mathrm{C}$ [9]. On the basis of this technology, Japan independently developed Mafilon (MFL), a deicing material, and paved the sustainedrelease snow melting asphalt pavement for the first time in 1986 [10]. So far, sustained-release snow-melting asphalt pavement has been successfully promoted in most parts of Japan. The technology was first introduced in China in 2008 and successively built test roads in Shanxi, Hubei, Heilongjiang, and other places [11-15].

Recently, experimental study on the effect of salt addition on pavement performance of asphalt mixture has been carried out by Xu and Han [16], Gao et al. [17], and Zhang 


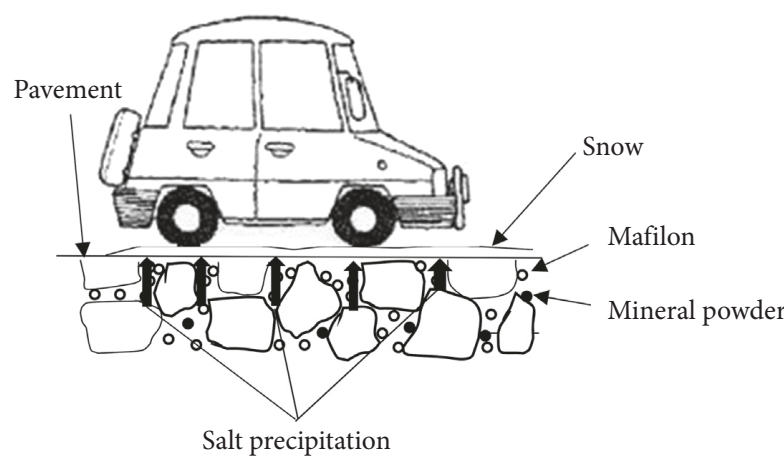

FIGURE 1: Schematic diagram of sustained-release snow melting asphalt pavement.

et al. [18]. They all found that the pavement performance, especially water stability of asphalt mixture, decreased obviously after Mafilon was added. Gao et al. [17] and Fu et al. [19] studied the mechanism of snow melting pavement. They indicated that the precipitation of chloride, the key component of snowmelt, reduces the freezing points of water and the interfacial adhesion between ice layer and pavement. Yu et al. [20], Wang et al. [21], and Xia et al. [22] have evaluated the effect of snow melting. Yu et al. [20] evaluated the snow melting effect of MFL-added specimens by the separation of sponge and specimen. Wang et al. [21] and Xia et al. [22] also qualitatively evaluated the effect of snow melting. Liu et al. [23] investigated influencing factors of salt precipitation and indicated that the higher the air void ratio, the greater the salt released out. However, the asphalt mixtures with a connected interspace will dissolve more salt than that with a closed internal space. Research status shows that there are still many defects in the research of sustained-release snow melting technology. The existing research mainly focuses on how the basic performance of the asphalt mixture varies after part of the mineral material is replaced. Research on longterm performance of sustained-release snow melting asphalt mixture and estimation of effective deicing period is hardly to find.

This paper aims to determine appropriate mixing amount of MFL by studying the short-term pavement performance of sustained-release snow melting asphalt mixture. In addition, long-term performance test of the pavement was used to study the changes in pavement performance with salt precipitates. Also, the precipitation rate of salt was measured by conductimetry to estimate the effective deicing period of the pavement. Finally, a new method called bond force test was developed to quantitatively evaluate the snow melting effect of the pavement.

\section{Materials and Experiments}

2.1. Materials. To realize the deicing function of the road surface, the deicing additive is added to the asphalt mixture in replacement of partial mineral powder. That is the biggest difference between sustained-release snow melting asphalt mixture and ordinary asphalt mixture.

As shown in Figure 2, the deicing additive used in this study is Mafilon (MFL for short) produced by a Japanese

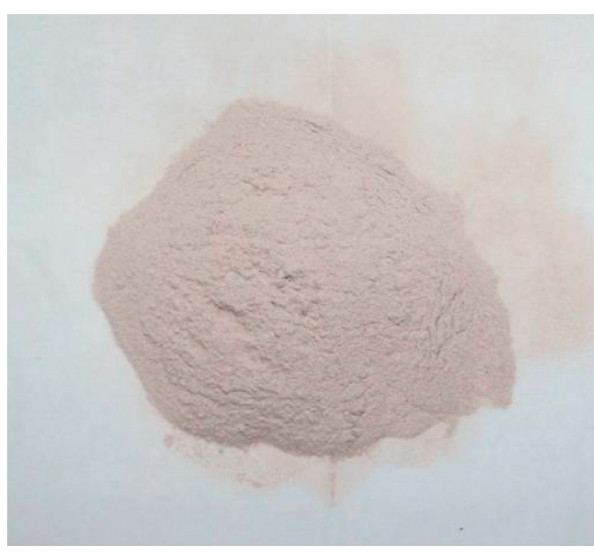

FIgURE 2: Mafilon.

company. The matrix material of the MFL is porous silica filled with massive salt including sodium chloride and calcium oxide. Some basic performance tests were carried out on MFL, and the test results are shown in Table 1. The test results show that most MFL particles are less than $0.075 \mathrm{~mm}$ in diameter, which is similar to mineral powder. Therefore, MFL was added to the asphalt mixture in replacement of partial mineral powder in this experiment. Meanwhile, the density of MFL is $2.25 \mathrm{~g} / \mathrm{cm}^{3}$ and that of mineral powder is approximately $2.65 \mathrm{~g} / \mathrm{cm}^{3}$; therefore, the density of MFL is smaller than that of mineral powder. If mineral powder is replaced by an equal mass of MFL, the volume of MFL is larger than that of mineral powder. As a result, the specific surface area and volume of the fine aggregate will increase [24]. An increase in the specific surface area will result in a thinning of the asphalt film, which lead to a decrease in water stability of the mixture. Furthermore, the increase of the fine aggregate volume will lead to the decrease of the void ratio of the mixture, which is not conducive to salt precipitation. Therefore, partial mineral powder was replaced by MFL by equal volume method in the experiment. Meanwhile, $71 \%$ by mass of MFL is soluble in water (mainly $\mathrm{NaCl})$.

Meanwhile, this study adopted the basalt aggregates, which were hard, wear-resistant, and good angularity. Furthermore, the basalt aggregates were basically nonabsorbent.

The styrene-butadiene-styrene- (SBS-) modified asphalt binder was used in this study. In addition, the basic properties of the binder are listed in Table 2.

With the SBS modified asphalt binder and basalt aggregates, the Stone Matrix Asphalt with the maximum nominal diameter of $13.2 \mathrm{~mm}$ (SMA13) was prepared. SMA is a hot asphalt mixture consisting of a coarse aggregate and a high binder content mortar $[25,26]$. In recent years, the SMA is widely applied on pavement of high-grade highways throughout the world due to its excellent performance [27].

For the SMA13, the experimental design gradation and the upper and lower limits are shown in Figure 3. According to the recommendations provided by the Chinese technical specifications [28], $0.3 \%$ lignin fiber was added to the mixture. The asphalt aggregate ratio was determined by the Marshall design method [29]. The parameters of the 
TABLE 1: MFL basic performance.

\begin{tabular}{lcc}
\hline Test item & Unit & Test result \\
\hline Appearance & - & Light red powdery substance \\
Density & $\mathrm{g} / \mathrm{cm}^{3}$ & 2.25 \\
Soluble salt content & $\%$ & 71.0 \\
Heating volatilization & - & Nonvolatile \\
\hline Main ingredients and content & \\
$\mathrm{Cl}$ & $\%$ & 41.93 \\
$\mathrm{Na}$ & $\%$ & 27.97 \\
$\mathrm{Ca}$ & $\%$ & 20.24 \\
$\mathrm{SiO}_{2}$ & $\%$ & 5.3 \\
\hline Particle size range & & \\
$<0.15 \mathrm{~mm}$ & $\%$ & 100 \\
$<0.075 \mathrm{~mm}$ & $\%$ & 98.2 \\
\hline
\end{tabular}

TABLE 2: Basic properties of SBS modified asphalt.

\begin{tabular}{lcccc}
\hline $\begin{array}{l}\text { Test } \\
\text { item }\end{array}$ & $\begin{array}{c}\text { Density } \\
\left(\mathrm{g} \cdot \mathrm{cm}^{-3}\right)\end{array}$ & $\begin{array}{c}25^{\circ} \mathrm{C} \text { penetration/ } \\
0.1 \mathrm{~mm}\end{array}$ & $\begin{array}{c}\text { Softening } \\
\text { point }\left({ }^{\circ} \mathrm{C}\right)\end{array}$ & $\begin{array}{c}5^{\circ} \mathrm{C} \text { ductility } \\
(\mathrm{cm})\end{array}$ \\
\hline $\begin{array}{l}\text { Test } \\
\text { result }\end{array}$ & 1.037 & 72 & 59 & 39 \\
\hline
\end{tabular}

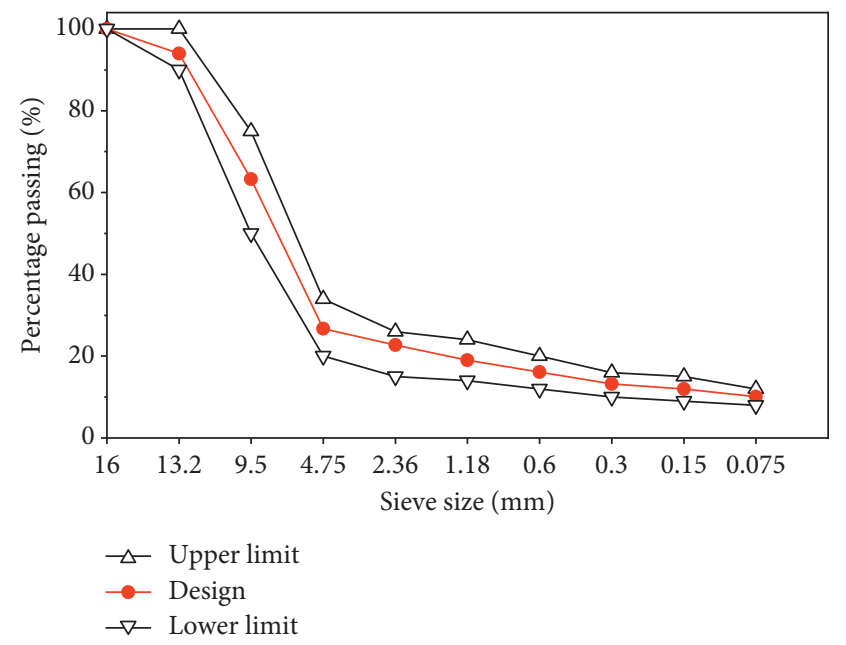

Figure 3: SMA-13 design gradation.

Marshall design are shown in Table 3. The final optimal asphalt-aggregate ratio is $5.8 \%$.

\subsection{Experiment}

2.2.1. Short-Term and Long-Term Pavement Performance Experiments. The physical and chemical properties of MFL are different from mineral powder. Since mineral powder is an important component of asphalt mixture, when MFL replaces part of mineral powder, the performance of sustained-release snow melting asphalt mixture is expected to be changed. Therefore, the short-term pavement performance of sustained-release snow melting mixture needs to be tested. Meanwhile, as the salt in MFL will gradually precipitate (Figure 4), pavement performance of the sustained-release snow melting asphalt mixture will vary with time. Therefore, long-term road performance experiments were added in this paper to ensure the service life of sustained-release snow melting asphalt pavement. For longterm road performance test, specimens were immersed in water for different days firstly. Since the precipitation amount of salt changes with time, specimens of different salt analysis degrees are obtained. By testing the road performance of these specimens, the variation of the road performance of the mixture with time can be obtained. To speed up salt precipitation, water was changed every 12 hours in the experiment.

The short-term pavement performance experiments in this paper include water stability, high temperature stability, and low temperature crack resistance; raveling resistance is added to long-term road performance on this basis. According to Standard Test Methods of Bitumen and Bituminous Mixtures for Highway Engineering [30], water stability, high temperature stability, low temperature crack resistance, and raveling resistance of asphalt mixture were evaluated by water immersion Marshall test, rutting test, low-temperature trabecular bending test, and Cantabro test. In short-term performance experiment, deicing additive replaces $0 \%, 35 \%, 70 \%$, and $100 \%$ of mineral powder, respectively, by volume. The specimens were prepared according to the above gradation, asphalt aggregate ratio, and fiber content. In the long-term performance experiment, $70 \%$ of mineral powder was replaced by the same volume of MFL. The specimens were immersed in water for $1,3,7$, and 15 days, respectively, before performance test. Figure 5 shows the flow chart of short- and long-term performance experiment.

2.2.2. Estimation of Effective Deicing Period. The effective deicing period of sustained-release snow melting asphalt pavement depends on three main factors. They are the total mass of soluble salt in the pavement, the precipitation rate of salt, and the local annual average precipitation days. Therefore, the effective deicing period was estimated by

$$
T=\frac{m}{(24 v t)},
$$

where $T$ is the effective deicing period (year), $m$ is the mass per square meter of soluble salt in the pavement $\left(\mathrm{g} / \mathrm{m}^{2}\right), v$ is the average precipitation rate $\left(\mathrm{g} /\left(\mathrm{m}^{2} \cdot \mathrm{h}\right)\right)$ of salt per square meter of pavement, and $t$ is the local average annual precipitation days (day).

Parameter $t$ was obtained by querying the statistics of the local climatic conditions. Then, $m$ was calculated by the thickness of snow melting asphalt pavement, the density of snow melting mixture, MFL mixing amount, and content of soluble salts in MFL. However, the final parameter $v$ is not directly available. Therefore, conductimetry was used to determine the precipitation rate of salt on the surface of specimen.

Conductimetry is an analytical method that determines concentration of the measured substance by measuring conductivity of a solution. In this paper, concentration of salt in water was measured by conductivity meter. Then $v$ 
TABLE 3: Marshall design parameters.

\begin{tabular}{lcccccc}
\hline Gradation type & $\begin{array}{c}\text { Asphalt aggregate ratio } \\
(\%)\end{array}$ & $\begin{array}{c}\text { Stability } \\
(\mathrm{kN})\end{array}$ & $\begin{array}{c}\text { Flow value } \\
(\mathrm{mm})\end{array}$ & $\begin{array}{c}\text { Theoretical density } \\
\left(\mathrm{g} \cdot \mathrm{cm}^{-3}\right)\end{array}$ & $\begin{array}{c}\text { Bulk volume density } \\
\left(\mathrm{g} \cdot \mathrm{cm}^{-3}\right)\end{array}$ & $\begin{array}{c}\text { Void ratio } \\
(\%)\end{array}$ \\
\hline \multirow{3}{*}{ SMA-13 } & 5.6 & 8.84 & 2.59 & 2.611 & 2.501 & 4.2 \\
& 5.9 & 8.66 & 2.48 & 2.601 & 2.503 \\
\hline
\end{tabular}

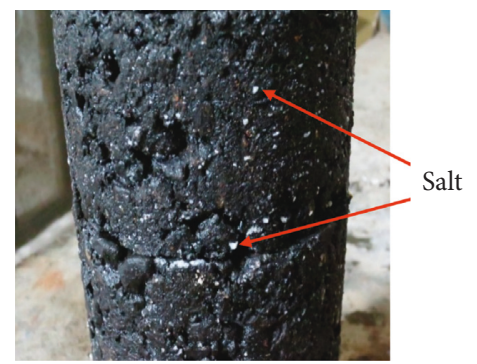

FIGURE 4: Surface salt precipitation of sustained-release snow melting mixture specimen.

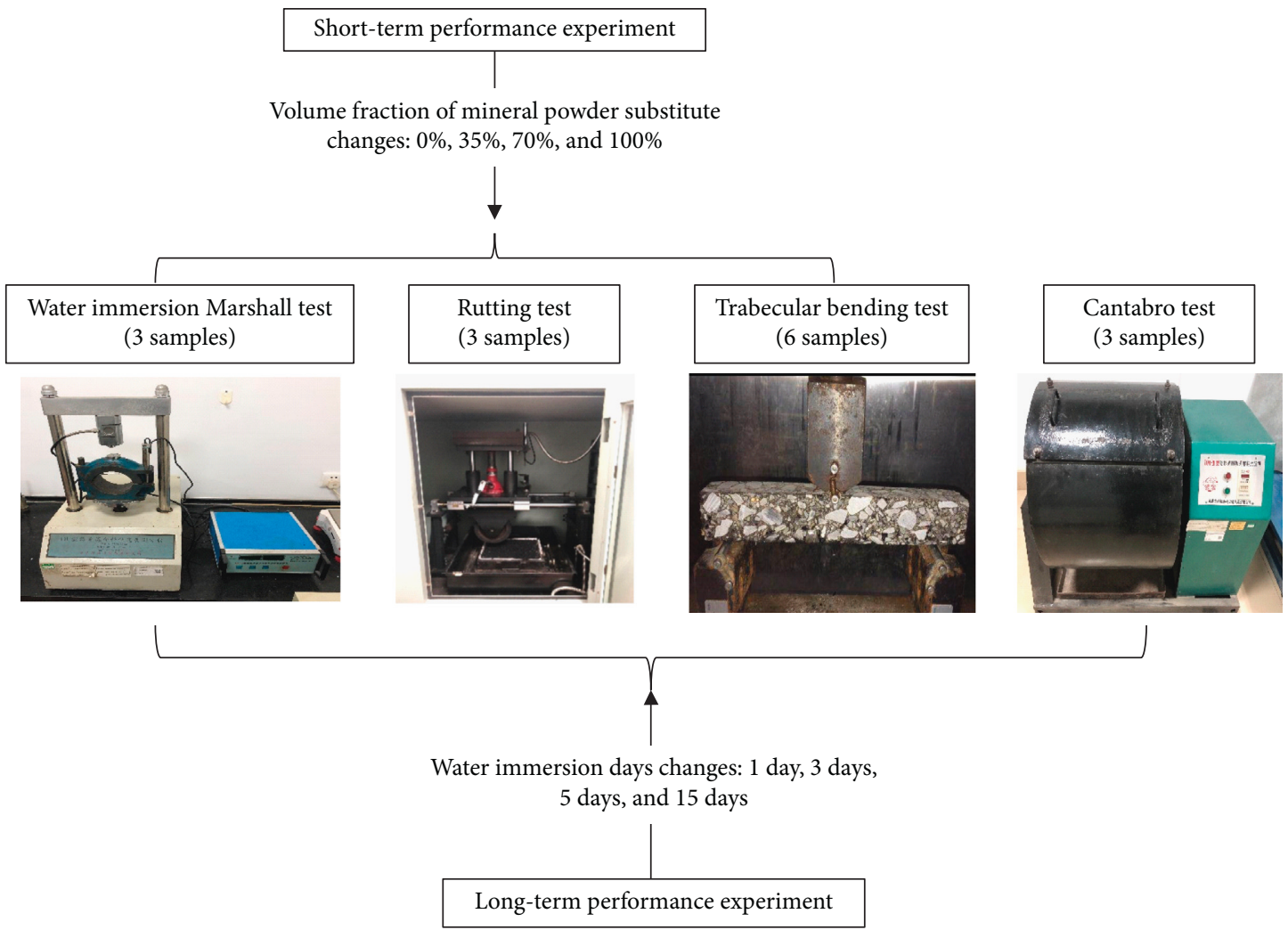

FIGURE 5: Flow chart of short- and long-term performance experiment.

was calculated by the increase of salt concentration, the volume of water, and the area of Marshall specimen. The instrument used in the experiment was MP515-01 conductivity meter produced by Shanghai Sanxin Company. The experimental process is shown in Figure 6.

2.2.3. Evaluation of Snow Melting Effect. Most of the methods for evaluating the effect of snow melting are qualitative. It is impossible to accurately evaluate the influence of
MFL content on the effect of snow melting. Therefore, a new quantitative evaluation method of snow melting effect called bond force test was developed in this paper.

The actual deicing process of snow melting pavement is that with the precipitation of salt, the bonding force between the ice layer and the pavement surface decreases. Then the snow separates from the road under the driving of the vehicle tires. Therefore, the bond force test reflects the snow melting effect of asphalt mixture by measuring the average adhesion stress between the ice and the mixture. 


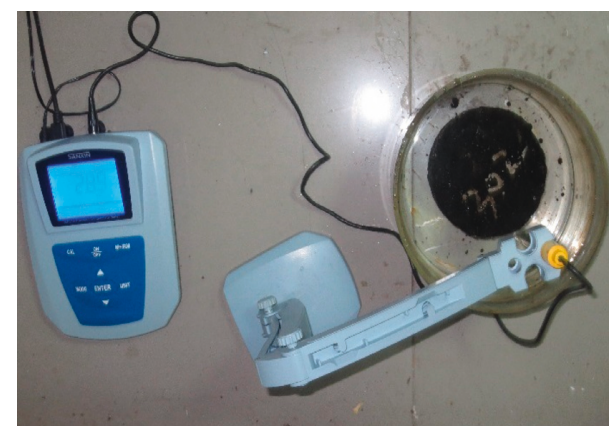

FIGURE 6: Conductivity meter for salt precipitation measurement.

The bond force test device is mainly composed of two parts: the clamp mold and the base mold. The two molds are, respectively, connected to SYD-0624 asphalt toughness tester to form the entire test device. The structural diagram and physical diagram of the experimental device are shown in Figure 7. In the schematic diagram, (1) is the asphalt mixture specimen, (2) is a rectangular cloth strip, (3) is a base mold, (4) is a clamp mold, (5) is a screw, (6) is a pallet, (7) is leaf spring, and (8) is a nut. The appearance of the clamp mold and the base mold is shown in Figure 8 . Considering that the adhesion between the cloth strip and the ice layer should be greater than that between the ice layer and the specimen as well as stability of the experimental data, a cotton strip was adopted in the experiment.

The asphalt mixture specimen with water on the surface was tightly attached to a wet cloth strip with no air bubbles left in the middle. Then the specimen was placed in a $-3^{\circ} \mathrm{C}$ low-temperature air bath at a prescribed temperature for more than 12 hours. After that, the specimens were taken out from the low-temperature air bath and quickly placed on the leaf spring. One end of the cloth strip was placed between the two pallets of the clamp mold, and the cloth strip was tightly clamped between the two pallets by screwing the nut. Finally, the asphalt toughness tester was started so that the clamp pulled the strip upwards at a speed of $500 \mathrm{~mm} / \mathrm{min}$ until the strip was completely separated from the specimen surface. The adhesion stress between the ice layer and the specimen was recorded every $0.5 \mathrm{~mm}$ to obtain distribution of the adhesion stress on the specimen surface.

In this paper, the adhesion of ice layer on the surface of ordinary SMA13 specimens and MFL-added specimens was compared, so that the effect of snow melting was quantitatively evaluated. Meanwhile, the influencing factors of snow melting effect of asphalt pavement were studied by testing the ice layer adhesion of different freezing times, void ratios, and MFL contents.

\section{Results and Discussion}

\subsection{Evaluation of Short- and Long-Term Pavement Performance}

3.1.1. Short-Term Pavement Performance. According to the previous experimental plan, the Marshall test was carried out on the sustained-release snow melting asphalt mixture with different mineral powder substitute volumes, and the results are shown in Figure 9(a). Similarly, water immersion Marshall test, rutting experiment, and trabecular bending experiment were conducted, and the results are shown in Figures 9(b)-9(d), respectively. In Figure 9, 0 represents a common asphalt mixture, 35, 70, and 100 represent volume fraction of mineral powder substitute in equivalent volume.

According to the Technical Specification for Construction of Highway Asphalt Pavements [28], Marshall stability, water immersion residual stability, dynamic stability, and maximum flexure tensile strain of SMA should not less than $6 \mathrm{kN}, 80 \%, 3000$ cycles/mm, $2500 \mu \varepsilon$, respectively. The dotted line in Figure 9 represents the standard value.

Figure 9(a) shows that with the increase of the proportion of mineral powder substitute, the Marshall stability decreases. Similarly, the water immersion residual stability, dynamic stability, and maximum flexure tensile strain decline, as shown in Figures 9(b)-9(d), respectively. The above analysis from Figures 9(a)-9(d) indicates that strength, water stability, high- and low-temperature performance decrease with the growing deicing salt proportion, respectively. In summary, addition of deicing salt has a negative impact on the asphalt mixture performance.

The MFL particles are porous silica filled with salt particles; therefore, the presence of pores results in its less strength than the mineral powder particles. Meanwhile, the adhesion of the asphalt to the MFL particles is affected by the presence of the salt particles. The adhesion of asphalt to other minerals is also affected by it [31-34]. Hence, with the increase of the proportion of mineral powder substitute, pavement performance of asphalt mixture decreases.

On the other hand, the proportion of MFL directly affects the deicing effect and service life of sustained-release snow melting asphalt pavement. The higher the proportion of MFL, the better the deicing effect and the longer the service life. Therefore, it is necessary to increase the amount of MFL. In summary, the optimal amount of MFL needs to be determined. According to the experimental results of Figure 9, when the volume fraction of mineral powder substitute is $70 \%$, Marshall stability, water immersion stability, dynamic stability, and maximum flexure tensile strain are greater than the lower limit of the specification. However, when the substitution ratio exceeds $70 \%$, the water stability of the mixture drops sharply, as shown in Figure 9(b). While the volume fraction of mineral powder substitute is $100 \%$, the water stability of the mixture does not meet the specifications. Therefore, the volume fraction of mineral powder substitute should not exceed $70 \%$.

3.1.2. Long-Term Pavement Performance. Long-term performance research of asphalt pavement is done through a wide range of data survey analysis and tests and results summary and systematically studying the impact of factors such as traffic load and environmental climate on pavement performance, thereby providing guidance and assistance in the design and construction maintenance of asphalt pavements [35]. In this paper, in addition to basic factors such as traffic load and environment, the long-term performance of sustained-release snow melting asphalt pavement will be 


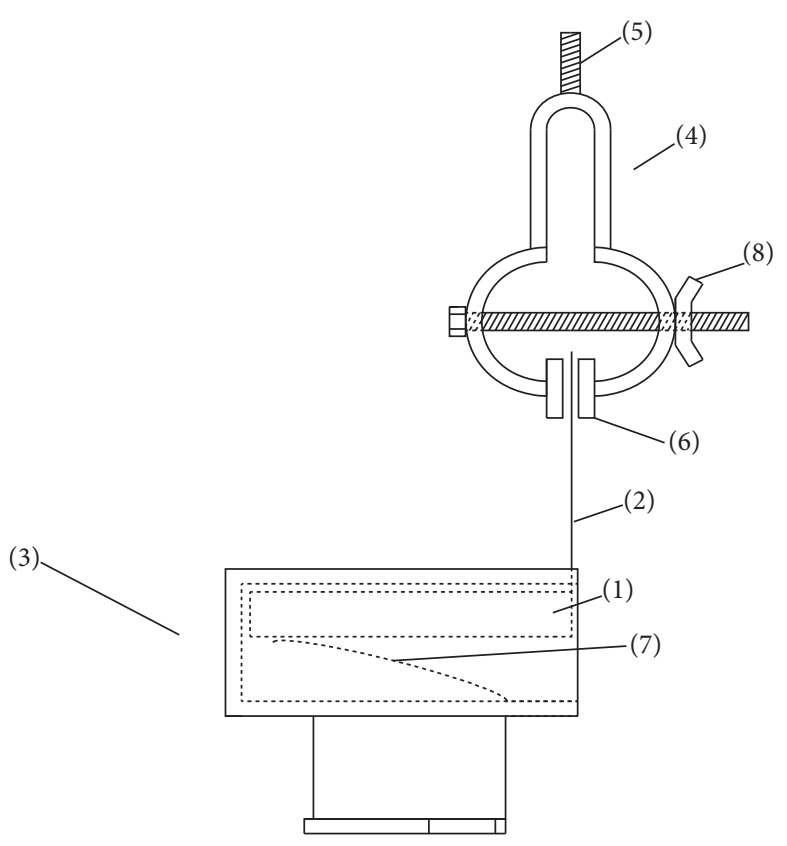

(a)

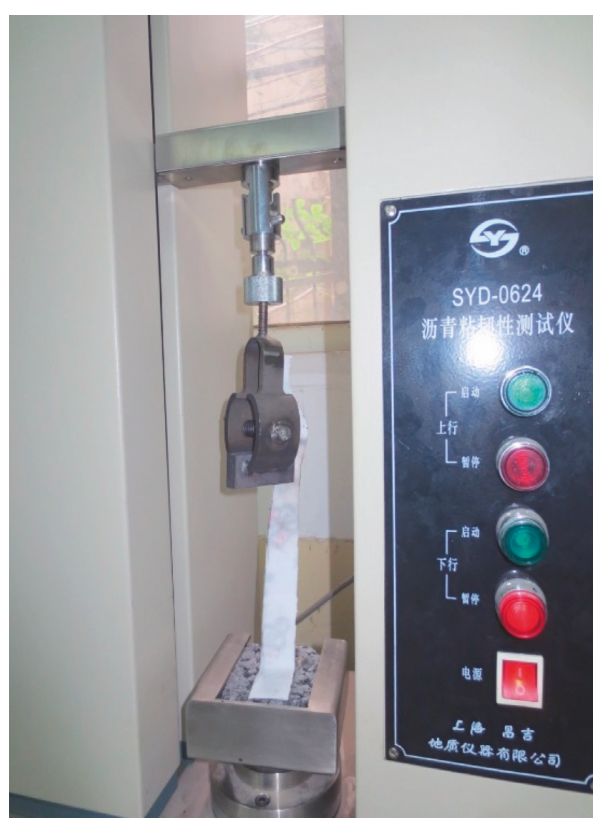

(b)

Figure 7: (a) Schematic diagram and (b) physical diagram of the experimental device.

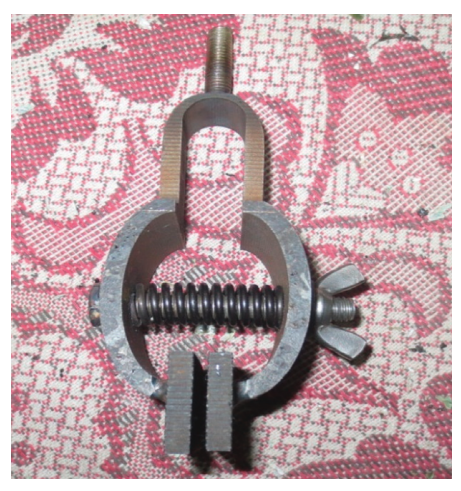

(a)

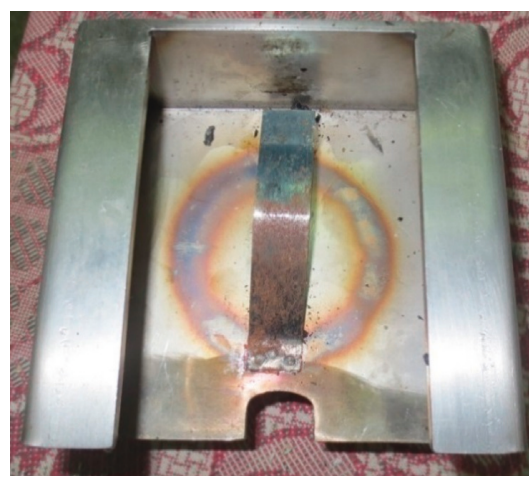

(b)

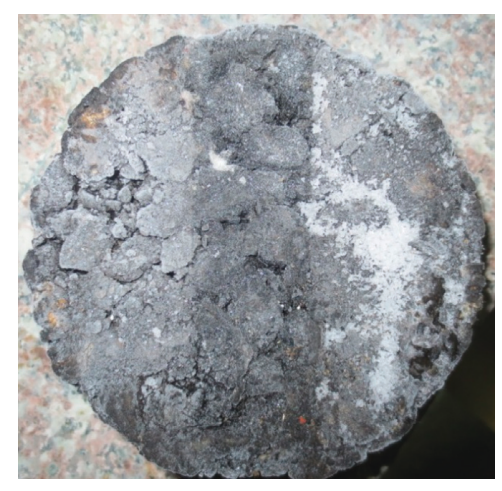

(c)

Figure 8: The pictures of various parts. (a) Clamp mold. (b) Base mold. (c) Specimen after test.

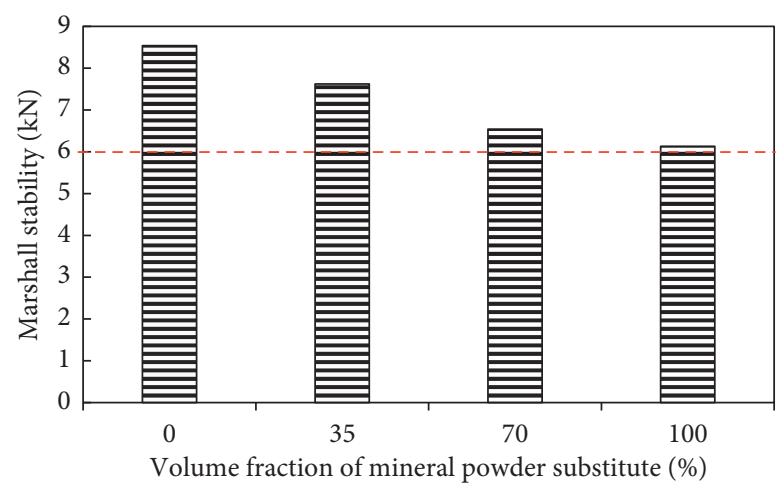

(a)

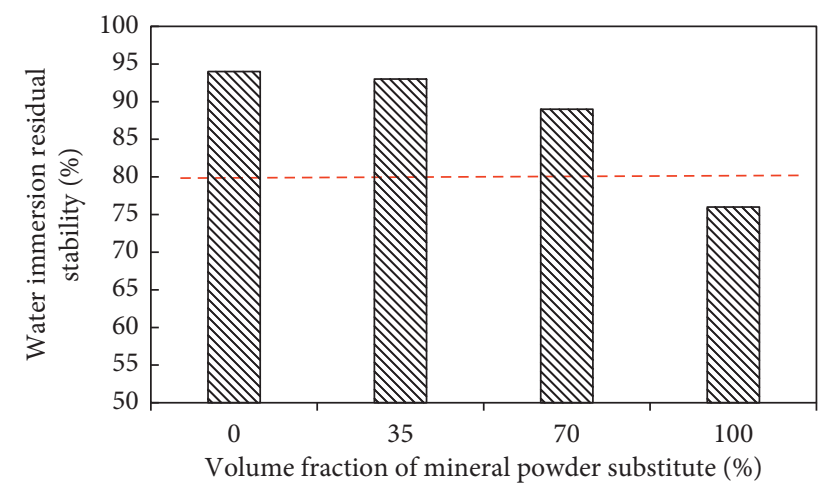

(b)

FIgURE 9: Continued. 


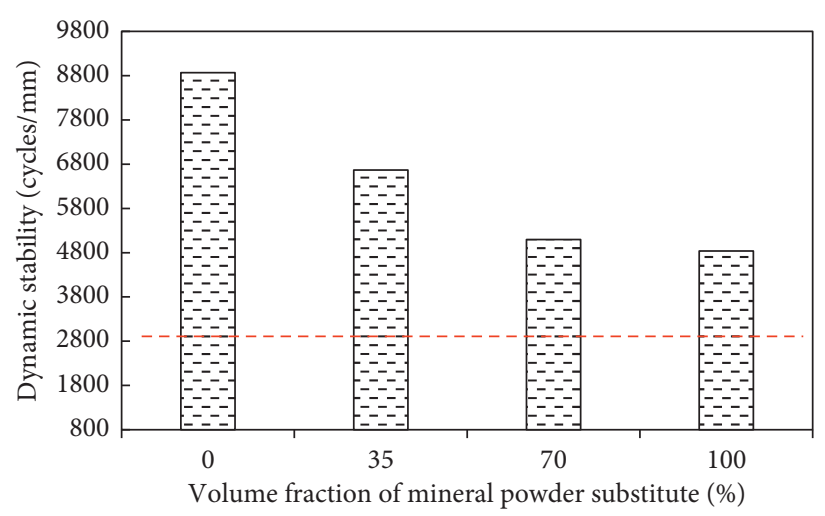

(c)

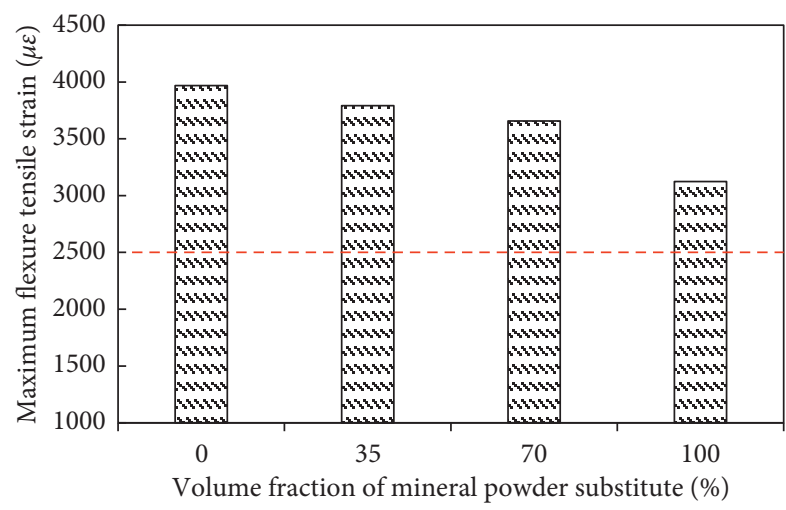

(d)

FIGURE 9: Short-term pavement performance test results.

seriously affected by salt precipitation. This is the biggest difference from ordinary asphalt pavement. To ensure the service life of sustained-release snow melting asphalt pavement, this study focuses on the impact of salt precipitation on the long-term performance of pavement.

The void ratio test was performed on the sustainedrelease snow melting asphalt mixture specimens with different immersion time, and the results are plotted in Figure 10(a). Similarly, the Marshall test, water immersion Marshall test, rutting test, trabecular bending test, and Cantabro test were conducted, and the results are shown in Figures 10(b)-10(f), respectively.

To verify if there is a significant difference in the performance of sustained-release snow melting asphalt mixture at different immersion times, the variance analysis was performed on the experimental data, and the results are shown in the Table 4.

Table 4 shows that $F$ is greater than the critical value of $F$ and $P$ values are less than 0.05 for all test data. Therefore, the water immersion days has a significant influence on the road performance.

Figures 10(a) and 10(b) show that as the immersion time is prolonged, void ratio of the specimen gradually increases, and Marshall stability decreases accordingly. It is because gradual salt precipitation leads to gradual appearance of pores of the porous silica, which increases porosity of the specimen. Meanwhile, salt precipitation leads to a decrease in the strength of the specimen, which affects Marshall stability.

Water stability of the asphalt mixture decreases with the immersion time. As shown in Figure 10(c), the ordinary specimen has higher water immersion Marshall residual stability than specimen mixed with MFL. With the extension of immersion time, the difference between the two shows an increasing trend. The experiment results indicate that the decrease in water stability of the MFL-mixed specimen is not only due to the influence of water immersion but also due to the precipitation of salt.

Figures $10(\mathrm{~d})$ and 10(e) show that with the extension of water immersion time, low-temperature performance and high-temperature performance of sustained-release snow melting mixture show a certain downward trend. However, the decrease is not significant. During the actual road use, the asphalt mixture will have some degree of aging, which will improve the high-temperature stability of the mixture. As a result, the effect of salt precipitation on high-temperature performance can be ignored. Meanwhile, the low-temperature performance after the decline can still ensure functional requirements of the pavement, so the effect of salt precipitation on low-temperature performance is not a major problem.

Figure 10(f) shows that as the water immersion time is prolonged, the mixture shows gradually increased Cantabro loss. The Cantabro loss of specimens immersed in water for 15 days is about three times that of specimens immersed in water for 1 day. It indicates that salt precipitation has a great influence on the raveling performance. The precipitation of salt changes the performance of the asphalt binder, resulting in a decrease in the adhesion between asphalt and aggregates, thereby reducing the raveling resistance of asphalt pavement. Under the action of traffic load, the aggregate of pavement will easily fall off and lose, forming looseness damage.

To ensure adhesion stress between asphalt and aggregates and to improve structural strength of the mixture, the performance of sustained-release snow melting mixture should be optimized. Hence, this study conducted the Cantabro test using polyester fiber in replace of lignin fiber, and the results are shown in Figure 11.

Figure 11 shows that after replacing lignin fiber with polyester fiber, the Cantabro loss of sustained-release snow melting mixture has greatly reduced. Although the Cantabro loss of the mixture still increases, the increase is small and the impact is almost negligible. Therefore, the replacement of lignin fiber by polyester fiber can improve the long-term raveling resistance of the mixture and guarantees that aggregates will not easily fall off when the salt is precipitated in a large amount.

3.2. Estimation of Effective Deicing Period. The deicing period of sustained-release snow melting asphalt pavement is a common concern. Only by estimating the deicing period can we know the failure time of the pavement, so that maintenance can be carried out in advance. 


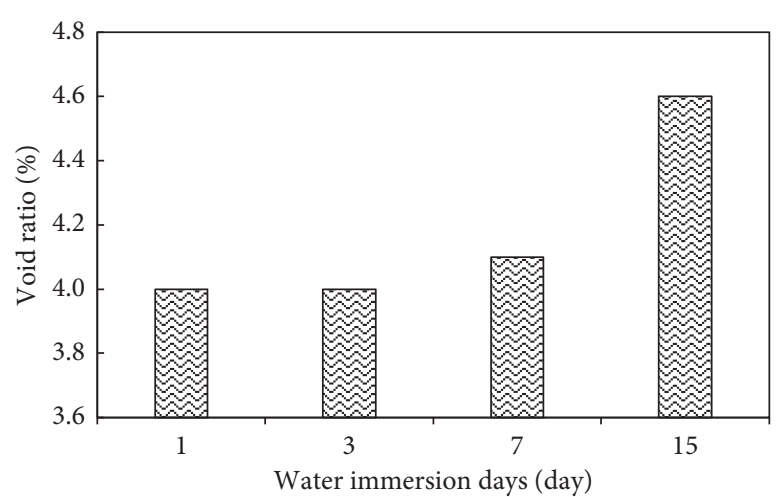

(a)

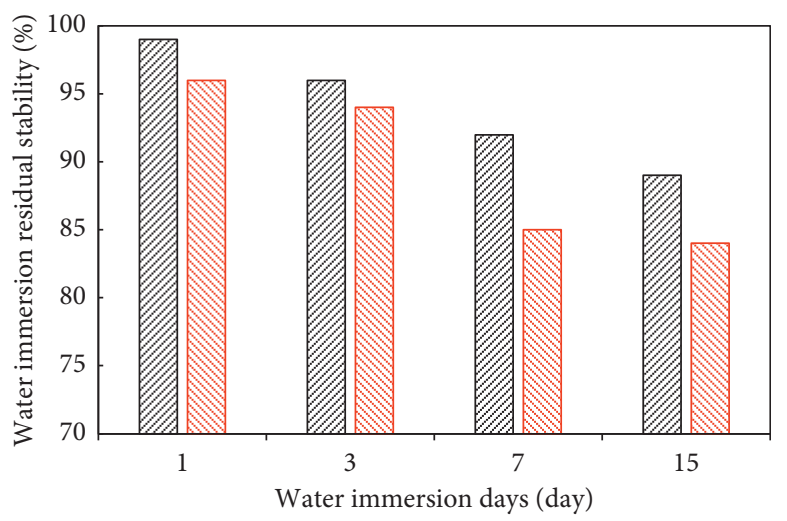

(7) No MFL added

MFL added

(c)

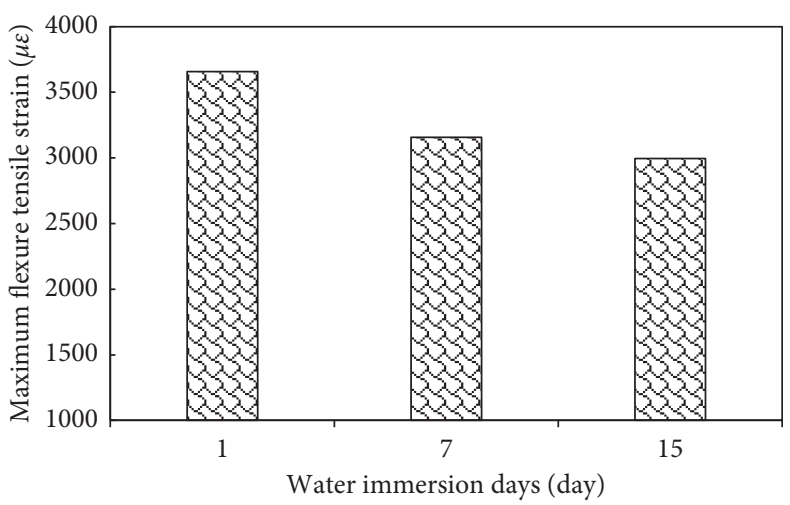

(e)

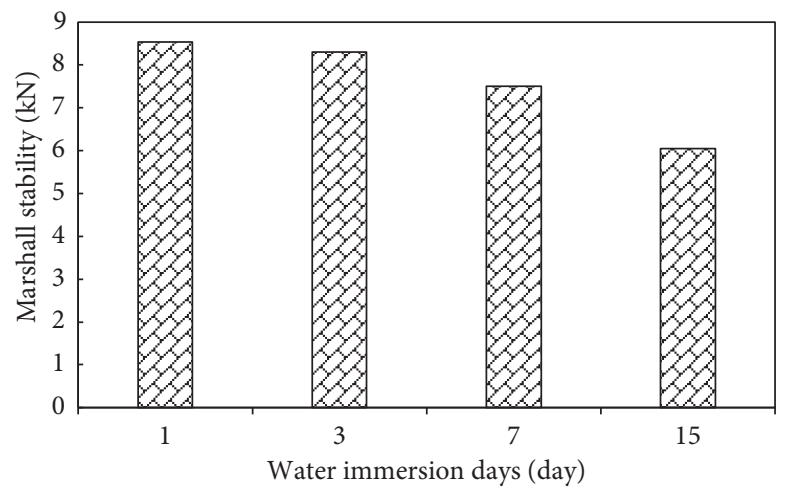

(b)

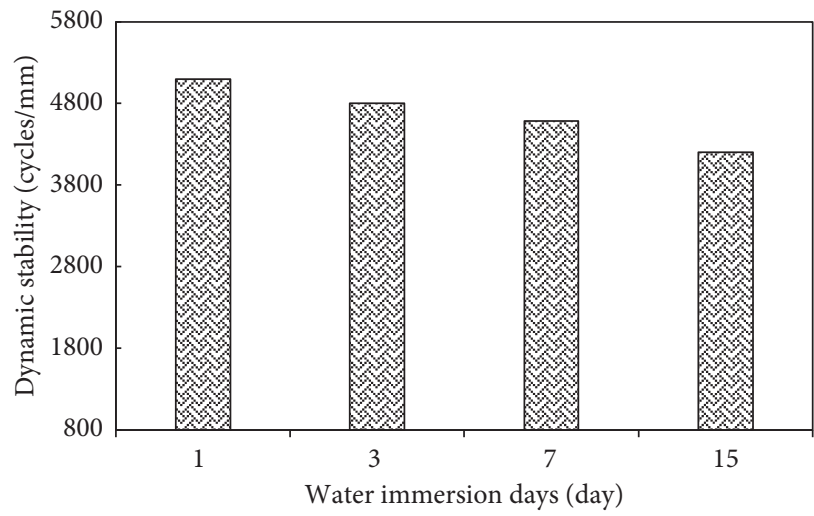

(d)

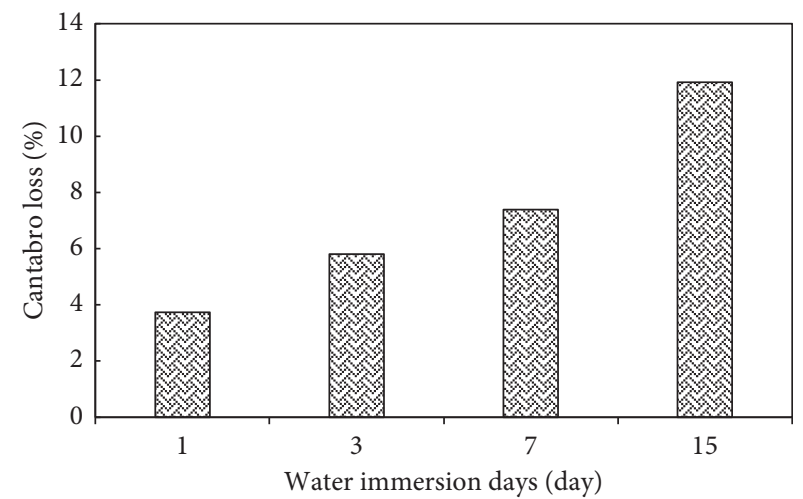

(f)

FIGURE 10: Long-term pavement performance test results.

Preparing specimens with $70 \%$ of mineral powder was replaced by the same volume of MFL. Immerse the specimens in water, and measure the concentration of the solution with a conductivity meter for one week. Convert the change in solution concentration to the precipitation rate of the salt. The converted salt precipitation rate results are shown in Figure 12.

Figure 12 shows that the salt precipitation rate is larger at the beginning of the measurement. It is because a certain amount of MFL will exist on the surface after the asphalt mixture specimen is formed. This part of salt is directly dissolved in the solution, leading to high salt precipitation rate at the beginning of the test. When the deicing salt on the specimen surface is completely dissolved, salt precipitation rate tends to be stable, fluctuating up and down at $0.45 \mathrm{~g} /$ $\left(\mathrm{m}^{2} \cdot \mathrm{h}\right)$. Therefore, the measured salt precipitation rate is about $0.45 \mathrm{~g} /\left(\mathrm{m}^{2} \cdot \mathrm{h}\right)$ for sustained-release snow melting pavement with $70 \%$ MFL mixing amount.

After the salt analysis rate has been measured, the mass of the soluble salt per square meter in the road surface can be calculated by the following parameters. They are the thickness of snow melting asphalt pavement, the density of snow melting mixture, the asphalt aggregate ratio of mixture, MFL mixing amount, and content of soluble salts in 
TABLE 4: Results of variance analysis.

\begin{tabular}{lccc}
\hline & $F$ & $P$ value & $F$ Crit \\
\hline Void ratio & 5.773 & 0.021 & 4.066 \\
Marshall stability & 4.948 & 0.031 & 4.066 \\
Water immersion residual stability & 5.943 & 0.020 & 4.066 \\
Dynamic stability & 30.802 & 0.003 & 6.591 \\
Maximum flexure tensile strain & 5.601 & 0.015 & 3.682 \\
Cantabro loss & 10.933 & 0.003 & 4.066 \\
\hline
\end{tabular}

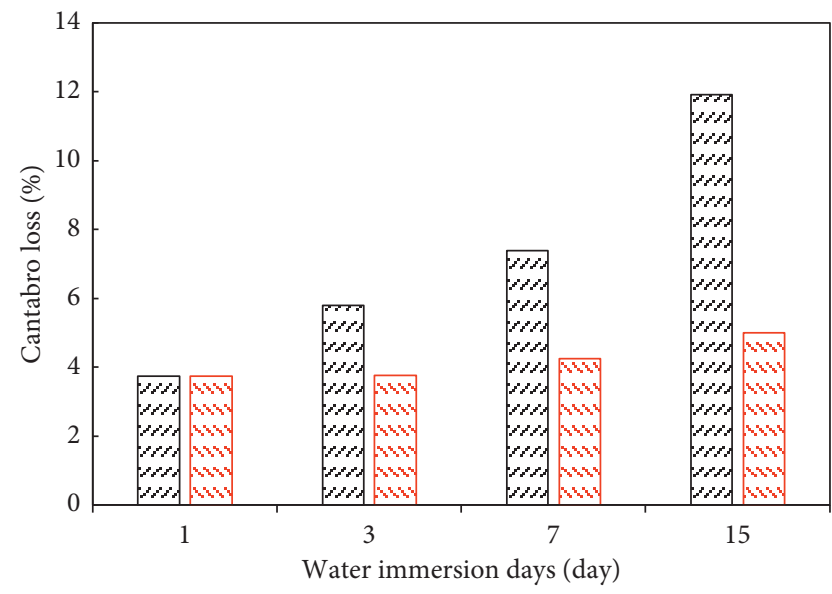

Q Lignin fiber

Q Polyester fiber

FIgURE 11: Raveling resistance of the two fiber mixtures with different water immersion days.

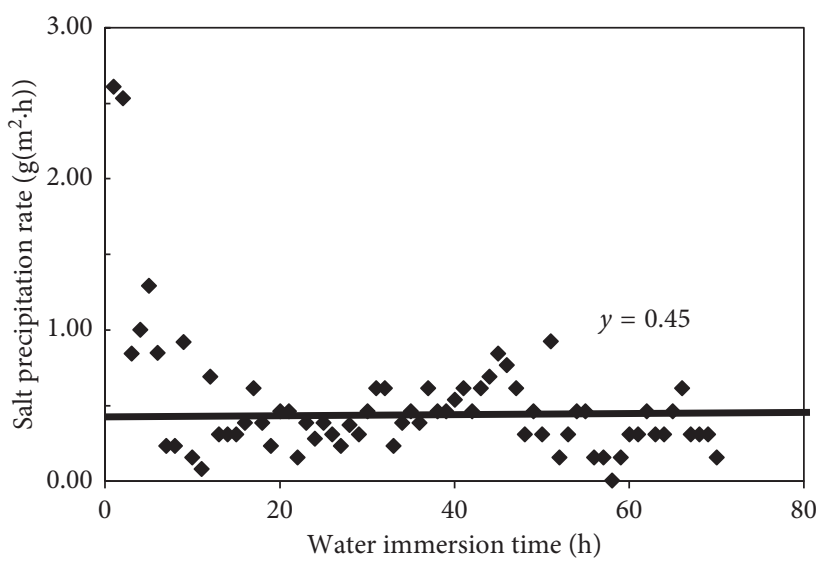

FIGURE 12: Salt precipitation rate versus time.

MFL. In this paper, sustained-release snow melting pavement has an asphalt aggregate ratio of $5.8 \%$ and a bulk volume density of $2.475 \mathrm{~g} / \mathrm{cm}^{3}$. The MFL quality accounts for $6 \%$ of the total mass of the mineral material, while the soluble salt content of the MFL is $71 \%$. The thickness of the pavement is $5 \mathrm{~cm}$. Therefore, the soluble salt mass per square meter of snow melting pavement is calculated to be $4982.75 \mathrm{~g}$.

Taking Jinan City, Shandong Province, China, as an example, effective deicing period of sustained-release snow melting pavement is calculated. It is found that the average annual precipitation days in the city is about 70 days, so the effective period of the snow melting pavement is

$$
T=\frac{m}{24 v t}=\frac{4982.75}{24 \times 0.45 \times 70}=6.6 \text { year. }
$$

As a result, effective deicing period of the sustainedrelease snow melting pavement in Jinan City, Shandong Province, is $6 \sim 7$ years.

\subsection{Evaluation of Snow Melting Effect}

3.3.1. Comparative Analysis of the Snow Melting Effect. To verify actual effect of the snow melting mixture, the comparative tests were performed with the ordinary and MFL-added specimens. These specimens were attached to the cloth strip and then were frozen in a box whose temperature was $-3^{\circ} \mathrm{C}$. After being frozen, the average adhesion stresses of the specimens were obtained to identify the actual effect of snow melting. The stress results are shown in Figure 13.

Figure 13 shows that the adhesion stress between MFLadded specimen and the ice layer is significantly lower than that between ordinary specimen and the ice layer. It indicates that snow melting asphalt mixture has a good effect of deicing and can reduce the adhesion of the ice layer to the pavement.

It is because the precipitation of salt reduces the freezing point of the water and inhibits the bond between the surface of the specimen and the ice. Therefore, the adhesion between the specimen and the ice layer is greatly reduced.

3.3.2. Factors Affecting Snow Melting Effect. To get better deicing effect, this paper further studies the three factors affecting the effect of snow melting. The three factors are freezing time, void ratio and MFL mixing amount.

(1) Freezing Time. The MFL-added specimens were frozen in a $-3^{\circ} \mathrm{C}$ air bath for $1 \mathrm{~h}, 3 \mathrm{~h}, 7 \mathrm{~h}, 14 \mathrm{~h}$, and $24 \mathrm{~h}$ respectively. Then, the adhesion stress between ice and the specimens was tested by bond force test. The adhesion stress of ordinary SMA specimens was also tested in this experiment. The experimental results of the adhesion stress of the two mixtures under different freezing times are shown in the Figure 14.

Figure 14 shows that after the specimen is frozen, the bonding strength between the cloth strip and the specimen is formed quickly, reaching a large value after $1 \mathrm{~h}$. Adhesion stress of the ordinary specimen gradually increases with the extension of freezing time. Conversely, with the extension of freezing time, adhesion stress of MFL specimen first increases rapidly in a short time, reaching a maximum value, and then gradually decreases. It is because the initial precipitation of the salt of the MFL specimen is small, the water on the surface of the specimen is quickly frozen, and the adhesion is rapidly increased. With the extension of time, the gradual salt precipitation destroys the adhesion stress between the ice layer and the specimen, making adhesion stress gradually decreased. 


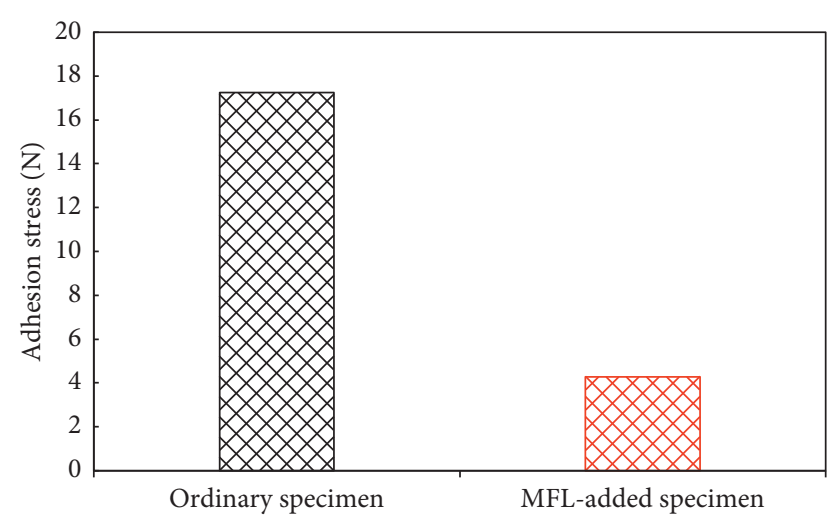

FIgURE 13: Adhesion test results of different specimens.

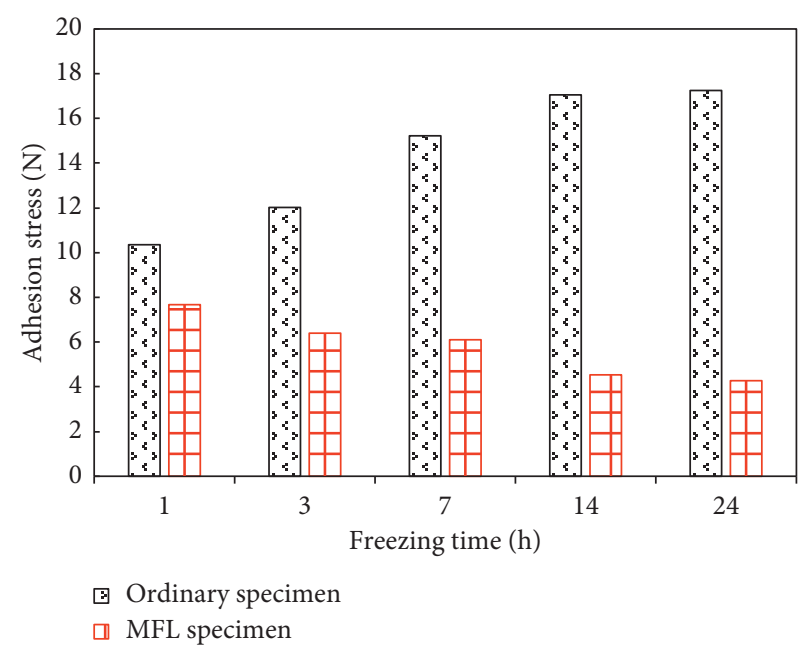

FIgURE 14: Adhesion variation with freezing time.

The results show that the presence of MFL in the mixture enables the pavement to have snow melting effect. However, freezing time possesses a certain influence on the snow melting effect, and the snow melting effect of the mixture gradually exerts with the prolongation of time.

(2) Void Ratio. To study the influence of void ratios on the effect of snow melting, it is necessary to form Marshall specimens with different void ratios. In this paper, the specimens with different void ratios were obtained by 30 times, 50 times, 75 times, and 90 times the beat of each Marshal specimen side. After specimens were formed, the variation of adhesion stress with void fraction was tested. The experimental results of adhesion stress under different void ratios are shown in Figure 15.

Figure 15 displays that as the void ratio of the specimen increases, the adhesion stress between the ice layer and the specimen gradually decreases and finally stabilizes. The reason is that an increase in the void ratio leads to an increase in the salt precipitation rate. More salt precipitates within the same time enhancing the damage of the bond between the ice layer and the specimen, thereby reducing the adhesion stress.

The experimental results show that the increase of void ratio can enhance effect of snow melting. Therefore, for

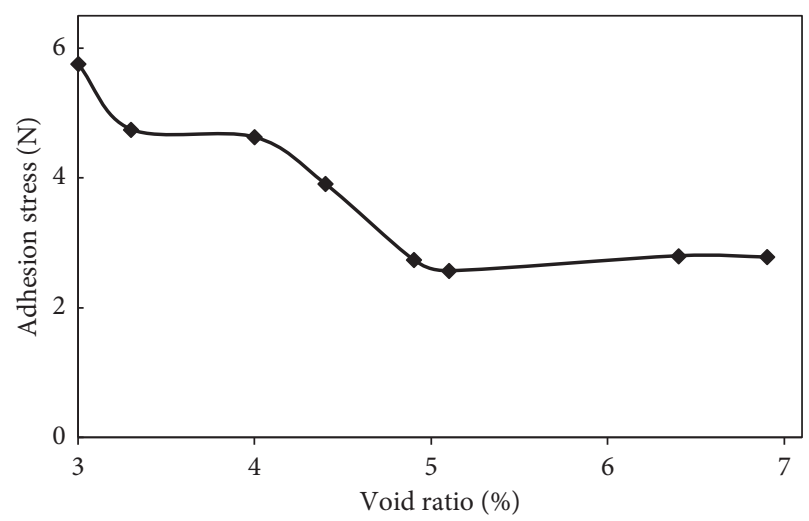

FIgURE 15: Adhesion variation with void ratio.

better snow melting effect, the void ratio can be appropriately increased. However, the effect of snow melting tends to be stable when the void ratio reaches $5 \%$, so the recommended void ratio of sustained-release snow melting asphalt mixture is $4 \%-5 \%$, slightly larger than ordinary SMA.

(3) MFL Mixing Amount. To study the influence of MFL mixing amount on the effect of snow melting, it is necessary to form Marshall specimens with different MFL content. In this study, the specimens with different MFL content were obtained by replacing $0 \%, 35 \%, 70 \%$, and $100 \%$ of mineral powder with an equal volume of MFL. After specimens were formed, the variation of adhesion stress with MFL mixing amount was tested. The results of the adhesion stress under different MFL mixing amounts are shown in Figure 16.

From Figure 16, with the increased MFL mixing amount, adhesion stress between the ice layer and the specimen gradually reduces. It is due to an increase in the MFL content resulting in an increase in salt concentration. Thereby, the precipitation of salt is speeded up from another way. More salt precipitates within the same time increases the damage of the bond between the ice layer and the specimen, reducing the adhesion stress.

The experimental results show that sustained-release snow melting mixture with larger MFL mixing amount has a better deicing effect. Considering that the addition of MFL has a negative impact on pavement performance, the suitable ratio of equal volume replacement of mineral powder with MFL is $70 \%$.

\section{Conclusion}

In this paper, the effects of MFL addition on short-term and long-term performance of sustained-release snow melting asphalt pavement were studied by laboratory experiments. Then, effective deicing period of asphalt pavement was estimated. Finally, a new experimental device was designed to evaluate the effect of snow melting and its influencing factors. The main conclusions are drawn as follows:

(1) The MFL mixing amount should not exceed $70 \%$ of the mineral powder by volume. Short-term 


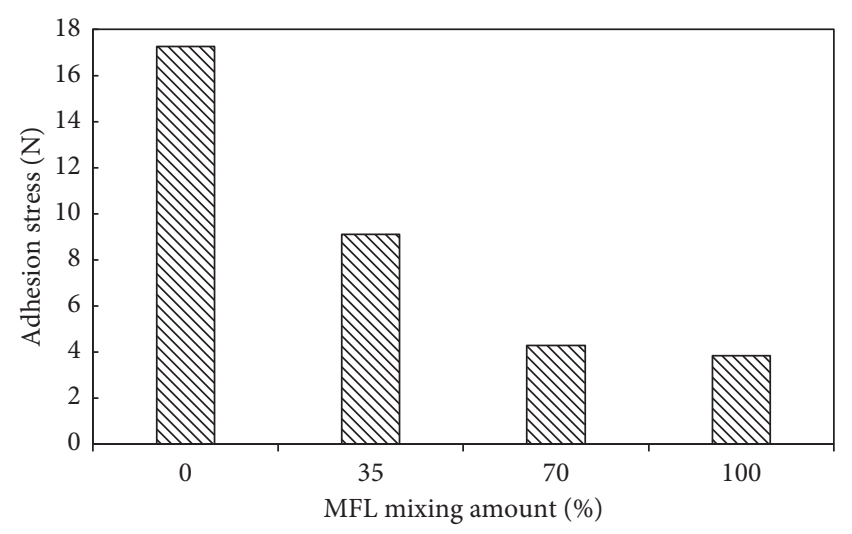

Figure 16: Adhesion variation with MFL mixing amount.

performance experiments indicate that the increase of MFL content causes the decrease of the strength, water stability, low- and high-temperature performances of the mixture.

(2) The precipitation of salt leads to a decline in the performance of sustained-release snow melting pavement. Long-term performance experiments show that salt precipitation weakens the strength, water stability, raveling resistance, low- and hightemperature performances of snow melting mixture.

(3) Replacing lignin fiber with polyester fiber can increase the adhesion of asphalt binder and consequently improve the long-term raveling resistance of the mixture. Long-term performance experiments suggest that the raveling resistance of the mixture is significantly reduced due to the precipitation of salt.

(4) Taking Jinan City, Shandong Province, China, as an example, the effective deicing period of sustainedrelease snow melting asphalt pavement built in this city is estimated to be $6 \sim 7$ years. Specifically, the effective deicing period of the pavement depends on the total mass of soluble salt in it, the precipitation rate of salt, and the local annual average precipitation days. Specially, the salt precipitation rate of the sustained-release type snow melting pavement with $70 \%$ MFL mixing amount is about $0.45 \mathrm{~g} /$ $\left(\mathrm{m}^{2} \cdot \mathrm{h}\right)$.

(5) Sustained-release snow melting asphalt mixture owns satisfactory deicing effect. Meanwhile, with the extension of freezing time, the increase of void ratio, and the increase of MFL mixing amount, the pavement has better deicing effect. Furthermore, the recommended void ratio is $4 \%-5 \%$.

\section{Data Availability}

The data used to support the findings of this study are included within the article.

\section{Conflicts of Interest}

The authors declare that they have no conflicts of interest.

\section{Acknowledgments}

This study was supported by the National Natural Science Foundation of China (51378123) and Postgraduates Research and Innovation Program in Jiangsu Province (KYLX15_0146 and KYLX_0167). The authors gratefully acknowledge their financial support. The authors would like to acknowledge all those who participated in the experiments on the sustained-release snow melting asphalt mixture. Further acknowledgements go to the Road Laboratory of Southeast University who provided instruments for the experiments. Additionally, all the authors of the following references are much appreciated.

\section{References}

[1] K. G. Bardal and F. Jørgensen, "Valuing the risk and social costs of road traffic accidents-seasonal variation and the significance of delay costs," Transport Policy, vol. 57, pp. 10-19, 2017.

[2] T. Aoyama, M. Ishikawa, T. Hira, and K. Ukigai, "Effect of surface roughness on adhesive shear strength between pure ice and a solid surface," Transactions of the Japan Society of Refrigerating and Air Conditioning Engineers, vol. 23, no. 3, pp. 273-281, 2006.

[3] S. Wu, P. Pan, M. Chen, and Y. Zhang, "Analysis of characteristics of electrically conductive asphalt concrete prepared by multiplex conductive materials," Journal of Materials in Civil Engineering, vol. 25, no. 7, pp. 871-879, 2013.

[4] J. Li, G. Liu, T. Yang, J. Zhou, and Y. Zhao, "Research on relationships among different distress types of asphalt pavements with semi-rigid bases in China using association rules mining: a statistical point of view," Advances in Civil Engineering, vol. 2019, Article ID 5369532, 15 pages, 2019.

[5] W. Wu, X. Yi, M. Guo, and L. Chen, "State of the art and practice of pavement anti-icing and de-icing techniques," Sciences in Cold and Arid Regions, vol. 6, no. 1, pp. 14-21, 2014.

[6] M. Kayama, A. M. Quoreshi, S. Kitaoka et al., "Effects of deicing salt on the vitality and health of two spruce species, Picea abies Karst., and Picea glehnii Masters planted along roadsides in northern Japan," Environmental Pollution, vol. 124, no. 1, pp. 127-137, 2003.

[7] E.-L. Thunqvist, "Regional increase of mean chloride concentration in water due to the application of deicing salt," Science of the Total Environment, vol. 325, no. 1-3, pp. 29-37, 2004.

[8] F. Augeri, Placement of Experimental Bituminous Concrete Mixture Utilizing an Asphalt Additive (Verglimit), Federal Highway Administration, Washington, DC, USA, 1987.

[9] E. C. Lohrey, Field Evaluation of an Experimental Bituminous Pavement Utilizing an Ice-Retardant Additive-Verglimit, Connecticut Department of Transportation Division of Research, Newington, CT, USA, 1992.

[10] Y. Araki, I. Takeda, and S. Suzuki, "Follow-up survey on powder/chloride freeze control pavement: survey cases of Europe and Japan," Pavement, vol. 32, no. 9, pp. 8-14, 1997.

[11] Y. Li, T. S. Li, Y. F. Xu et al., "Research and application of multifunction asphalt pavement with with snow melt salt," Journal of China \& Foreign Highway, vol. 32, no. 6, pp. 85-89, 2012.

[12] Y. J. Bai, Evaluate on the Performance of Snow Melt Salt Asphalt Mixture, Chang'an University, Xi'an, China, 2012. 
[13] Z. R. Sun, "Develop and performance evaluate of sustainedrelease mixture include salt," Master's thesis, Harbin Institute of Technology, Harbin, China, 2012.

[14] X. N. He, "Study on performance impact for polyester fibers into melting ice and snow MFL-asphalt mixture," Highway Engineering, vol. 39, no. 4, pp. 282-285, 2014.

[15] J. Sun, Z. D. Qian, and S. Luo, "Test and evaluation of road performance of ice-melting asphalt mixture," Highway, vol. 12, pp. 204-207, 2013.

[16] O. M. Xu and S. Han, "Effect of salt on the performance of salt storage asphalt mixture," Journal of Chang'an University (Natural Science Edition), vol. 35, no. 4, pp. 8-12, 2015.

[17] F. L. Gao, B. X. Hu, H. Huang et al., "Research of bridge deck anti-icing performance test base on mixed antifreeze materials," Highway Engineering, vol. 40, no. 1, pp. 229-273, 2015.

[18] H. J. Zhang, X. S. Wang, D. Z. Wu et al., "Test and study of road performance of $\mathrm{v}-260$ automatic anti-freezing asphalt mixture," Highway, vol. 8, no. 8, pp. 26-29, 2015.

[19] J. Y. Fu, C. Peng, Z. J. Zhao et al., "Effect of rain on beltdeicing performance of asphalt pavement containing deicing additive," Journal of Wuhan University of Technology, vol. 37, no. 2, pp. 50-54, 2015.

[20] W. S. Yu, X. C. Zhang, and K. Zhong, "De-icing performance of asphalt mixture with snowmelt agent and high-elastic modified asphalt binder," Journal of China University of Mining \& Technology, vol. 44, no. 5, pp. 912-916, 2015.

[21] W. F. Wang, D. S. Wu, C. Y. Wu et al., "Research on road performance and optimal design of sustained-release antifreeze SMA," New Building Materials, vol. 7, pp. 42-45, 2016.

[22] H. Y. Xia, F. F. Li, L. F. Song et al., "Preparation and performance evaluation of auto-snowmelt material," Highway, vol. 7, pp. 269-274, 2015.

[23] Z. Z. Liu, J. Gao, Z. W. Zang et al., "Analysis of road performance and salt releasing characteristics of antifreeze asphalt concrete," Highway, vol. 8, no. 8, pp. 200-204, 2016.

[24] S. Zhang, Y. Li, B. Shen, X. Sun, and L. Gao, "Effective evaluation of pressure relief drilling for reducing rock bursts and its application in underground coal mines," International Journal of Rock Mechanics and Mining Sciences, vol. 114, pp. 7-16, 2019.

[25] J. Li, M. Shang, G. Liu et al., "Two-step improvements of volumetric design method based on multi-point supported skeleton for asphalt mixtures," Construction and Building Materials, vol. 217, pp. 456-472, 2019.

[26] W. Xia, T. Xu, and H. Wang, "Thermal behaviors and harmful volatile constituents released from asphalt components at high temperature," Journal of Hazardous Materials, vol. 373, pp. 741-752, 2019.

[27] D. V. Thanh and C. P. Feng, "Study on Marshall and rutting test of SMA at abnormally high temperature," Construction and Building Materials, vol. 47, pp. 1337-1341, 2013.

[28] Ministry of Transport of the People's Republic of China, Technical Specification for Construction of Highway Asphalt Pavements, China Communications Press, Beijing, China, 2004.

[29] Ministry of Transport of the People's Republic of China, Standard Specification for Construction of Highway Asphalt Pavements, China Communications Press, Beijing, China, 2004.

[30] Ministry of Transport of the People's Republic of China, Standard Test Methods of Bitumen and Bituminous Mixtures for Highway Engineering, China Communications Press, Beijing, China, 2011.

[31] F. Gu, Y. Zhang, X. Luo, R. Luo, and R. L. Lytton, "Improved methodology to evaluate fracture properties of warm-mix asphalt using overlay test," Transportation Research Record: Journal of the Transportation Research Board, vol. 2506, no. 1, pp. 8-18, 2015.

[32] F. Gu, X. Luo, Y. Zhang, and R. L. Lytton, "Using overlay test to evaluate fracture properties of field-aged asphalt concrete," Construction and Building Materials, vol. 101, pp. 1059-1068, 2015.

[33] J. Zhang, F. Yang, J. Pei, S. Xu, and F. An, "Viscositytemperature characteristics of warm mix asphalt binder with sasobit," Construction and Building Materials, vol. 78, pp. 34-39, 2014.

[34] Y. Zhang, R. Luo, and R. L. Lytton, "Characterizing permanent deformation and fracture of asphalt mixtures by using compressive dynamic modulus tests," Journal of Materials in Civil Engineering, vol. 24, no. 7, pp. 898-906, 2012.

[35] J. D. Ren, "Development situation of long-term performance of asphalt pavement research," Northern Communications, vol. 5, pp. 63-66, 2016. 


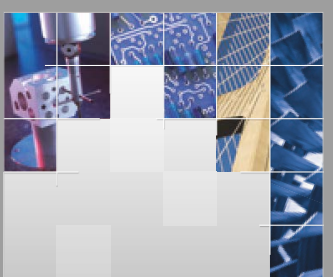

\section{Enfincering}
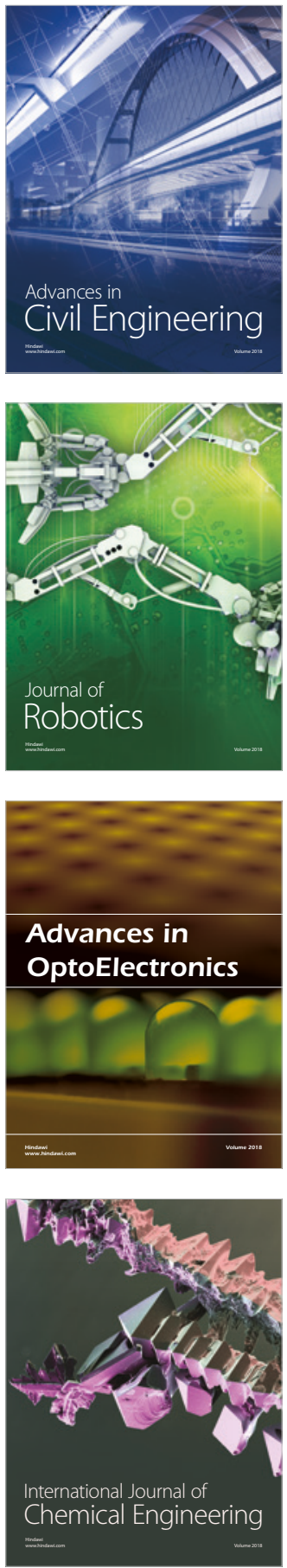

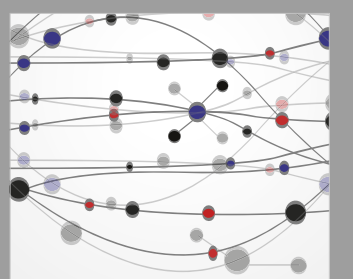

\section{Rotating \\ Machinery}

The Scientific World Journal

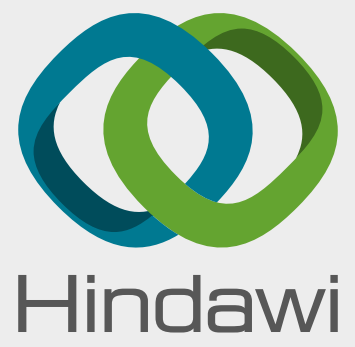

Submit your manuscripts at

www.hindawi.com
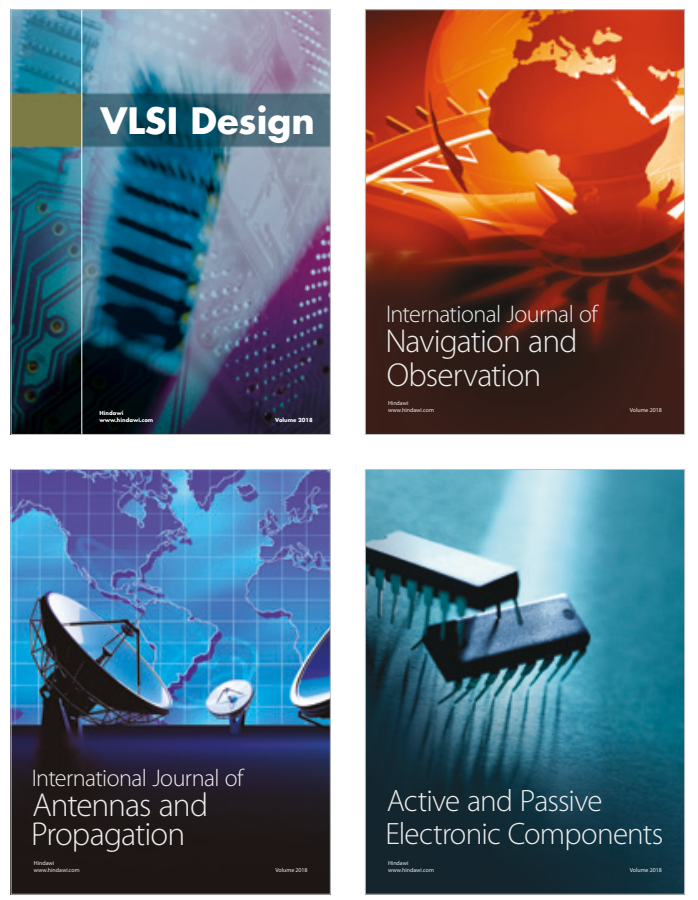
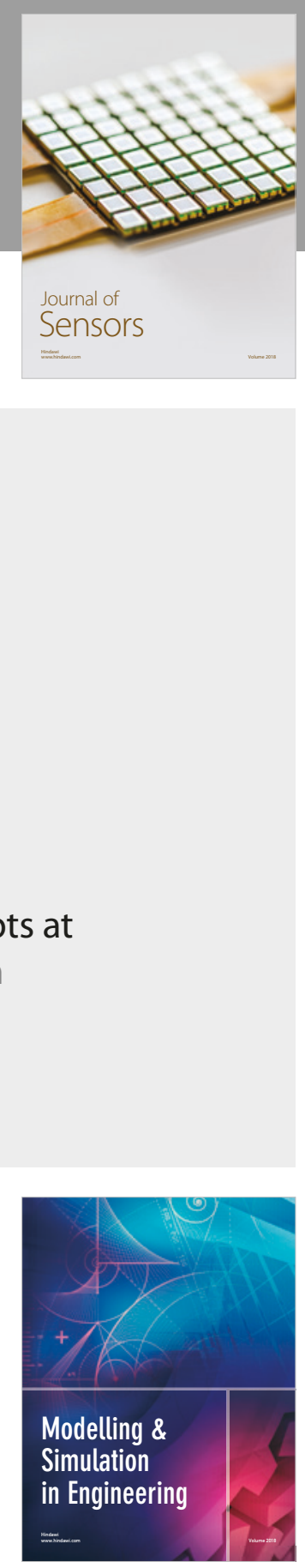

\section{Advances \\ Multimedia}
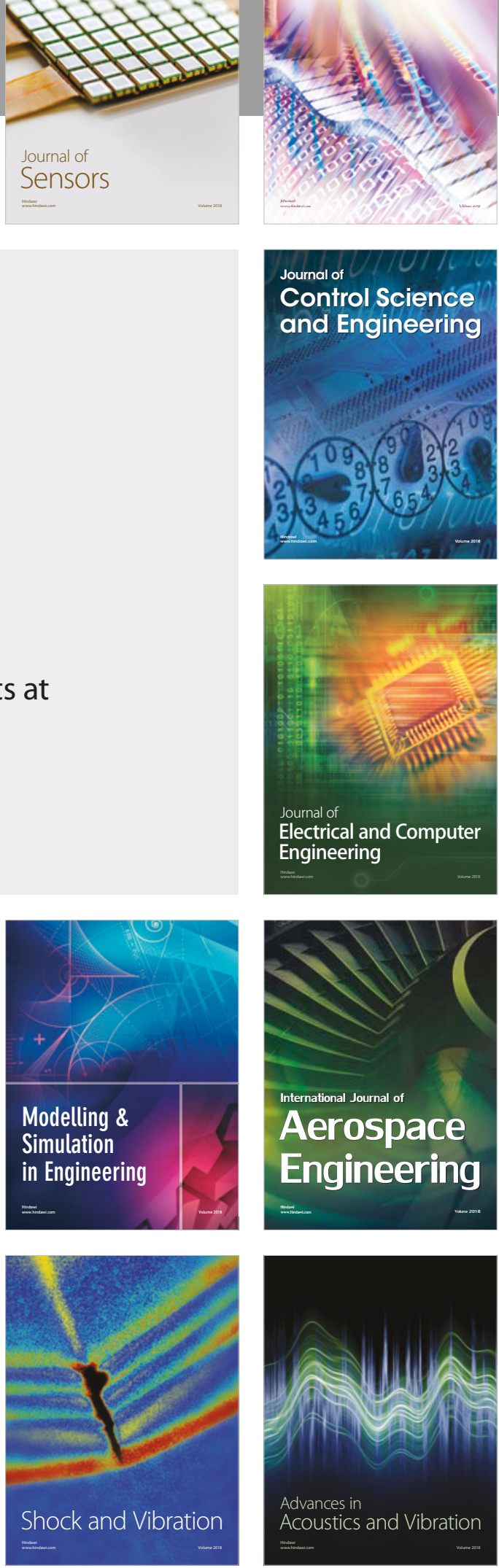